\title{
NNRTI (Non-Nucleoside Reverse Transcriptase Inhibitor) Drug AZT and Their Preparation \& Determination A Patent Evaluation of Efavirenz
}

\author{
Krishna sarmapathy* \\ Department of Organic Chemistry, Head IPL research Centre, India
}

Submission: April 04, 2019; Published: May 20, 2019

*Corresponding author: Krishna Sarmapathy, Department of Organic Chemistry, Head IPL research Centre, India

\begin{abstract}
Human immunodeficiency virus type-1 (HIV-1) is the causative agent for the transmission and development of the acquired immunodeficiency syndrome (AIDS).Efavirenz (II) a potent NNRTI, is a significant component of a very effective (protease sparing) regimen when co administered with AZT and 3TC [1]. Importance of Efavirenz led to the development of several strategies for its synthesis, and preparation was described in this paper, the world great potential drug Efavirenz still inaccessible to millions of people because of its atom economy and toxic [2]. Patent evaluation on process patents and well defined summary of patents . During the course of drug development most of the world pharmaceutical companies attempt well in the handling of environment friendly Efavirenz development especially Merck. We have surprisingly found that compound of Efavirenz can be prepared in good yield and high purity by Cyclisation of compound of (S)-2-(2-amino-5-chlorophenyl)-4-cyclopropyl-1,1,1trifluorobut-3-yn-2-ol with urea. Finally, Analytical method for determination Efavirenz has the absorbance maxima at $561 \mathrm{~nm}$ for the first order derivative visible-Spectrophotometric method.
\end{abstract}

Keywords: HIV-1; AIDS; AZT; DTG Benz oxazinones; Efavirenz; Urea; Cyclisation; crystallization; UV; spectrophotometric method; ART; CPA

\section{Efavirenz, DMP 266}

Efavirenz, L-743725((+)-enantiomer), DMP-266, L-741211(racemate), L-743726, Stocrin, Sustiva (S)-(-)-6-Chloro-4-(cyclopropylethynyl)-4-(trifluoromethyl)-2,4-dihydro-1H-3,1-benzoxazin-2-one. Now India recommends efavirenz (EFV)- based antiretroviral treatment (ART) to treat HIV, which is currently cheaper than DTG-based ART. However, as pharmaceutical licenses on DTG are now lifting in India, generic versions of DTG are likely to bring its cost close to that of EFV. Research from the USA and Europe, where DTG is recommended as the first option for treatment, suggests DTG has more tolerable side effects, can enable people to suppress HIV levels quickly and is less likely to lead to drug resistance [3].

As a result, DTG's use in these countries has substantially reduced the number of people who fail first-line treatment and are lost to care or require a switch to second-line ART. Using a mathematical simulation model of how HIV can advance and how it responds to treatment, the study, published by the Journal of International AIDS Society, examined the clinical and economic impact DTG could have on India's HIV response in comparison to EFV. Researchers found using DTG as the first option for HIV treatment would be cost-effective, and potentially cost-saving, for India's public health system. At 48 weeks, modellingsuggests
$90 \%$ of people on DTG would be virally suppressed compared to $82 \%$ of those on EFV. Longer term, DTG was projected to increase the proportion of people living with HIV on treatment who were still alive after five years from $76.7 \%$ to $83 \%$.Crucially, researchers found DTG had the potential to avert 13,000 new HIV infections over five years, equivalent to a $20 \%$ decrease in HIV incidence, resulting in a saving of US\$800,000 in projected care costs. When all factors are taken into account, care costs for the number of people initiating treatment on EFV were estimated to be US $\$ 139$ million at two years and US $\$ 590$ million at five years. In comparison, the care costs for DTG at two years was found to be lower at US\$137 million and cost-neutral at five years at US\$590 million. Cost increases linked to DTG were identified by the model, although these reflect the fact that more people are likely to live longer when on DTG, incurring greater lifetime care costs [4].

As a result, the authors recommend that when generic DTG becomes available in India, if priced at no more than $\$ 180$ per person per year, it would be cost-effective for India to switch to DTG as first-line treatment.

The research is particularly timely as India changed its treatment guidelines in 2017 to recommend that people living with HIV start treatment as soon as possible, regardless of their 
CD4 count. As a result, the cost of ART is becoming an increasingly central consideration to ensure treatment can be provided to all those now eligible.

\section{Merck Synthesis of Efavirenz- History}

Efavirenz was approved by the FDA on September 21, 1998, making it the 14th approved antiretroviral drug. Efavirenz is a non-nucleoside reverse transcriptase inhibitor being studied clinically for use in the treatment of HIV infections and AIDS. Efavirenz chemically known as (-) 6-Chloro-4-cyclopropylethynyl4-trifluoromethyl- 1, 4- dihydro-2H-3, 1-benzoxa zin-2-one, is a highly potent non-nucleoside reverse transcriptase inhibitor (NNRTI).A number of compounds are effective in the treatment of the human immunodeficiency virus (HIV) which is the retrovirus that causes progressive destruction of the human immune system. Effective treatment through inhibition of HIV reverse transcriptase is known for non- nucleoside-based inhibitors. Benz oxazinones have been found to be useful non-nucleosidebased inhibitors of HIV reverse transcriptase.(-) $\beta$-chloro ${ }^{\wedge}$ cyclopropylethyny M-trifluoromethyl-l ,4-dihydro-2H-3,l -ben zoxazin-2-one (Efavirenz) is efficacious against HIV reverse transcriptase resistance [5]. Due to the importance of (-)6-chloro4-cyclopropylethynyl-4-trifluoromethyl-1,4-dihydro-2H-3,l-ben zoxazin-2- one, economical and efficient synthetic processes for its production needs to be developed. The product patent US5519021. discloses the preparation of Efavirenz, in Example-6, column-29, involving cyclisation of racemic mixture of 2-(2-amino5-chlorophenyl)-4- cyclopropyl-1,l,l-trifluoro-3-butyn-2-ol using l, l '-carbonyl diimidazole as carbonyl delivering agent to give racemic Efavirenz. Further, resolution of the racemic Efavirenz is carried out using (-) camphanic acid chloride to yield optically pure Efavirenz. However, research article published in the Drugs of the future, 1998, 23(2), 133-141 discloses process for manufacture of optically pure Efavirenz. The process involves cyclisation of racemic 2-(2-amino-5-chlorophenyl)-4-cyclopropyl-l, 1, l-trifluoro-3-butyn-2- ol using 1, 1-carbonyldiimidazole as carbonyl delivering agent to give racemic Efavirenz and further resolution by (-) camphanic acid chloride [6]. Similarly, research article published in Synthesis 2000, No. 4, 479-495 discloses stereo selective synthesis of Efavirenz (95\%yield, 99.5\%ee), as shown below (Figure 1).

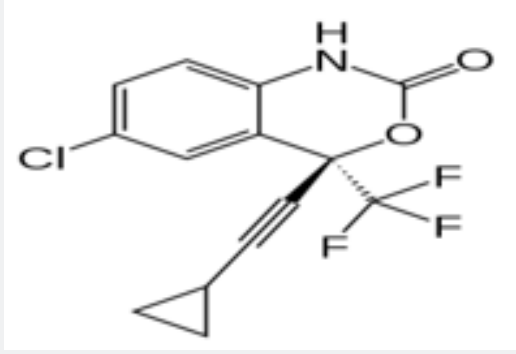

Figure 1: Efavirenz ,DMP 266.

Even though many prior art processes report method for the preparation of Efavirenz, each process has some limitations with respect to yield, purity, plant feasibility etc. Hence in view of the commercial importance of Efavirenz there remains need for an improved process. US 6028237 discloses a process for the manufacture of optically pure Efavirenz. The synthesis of efavirenz and structurally similar reverse transcriptase inhibitors are disclosed in US Patents 5,519,021, 5,663,169, 5,665,720 and the corresponding PCT International Patent Application WO 95/20389, which published on August 3, 1995 [7].

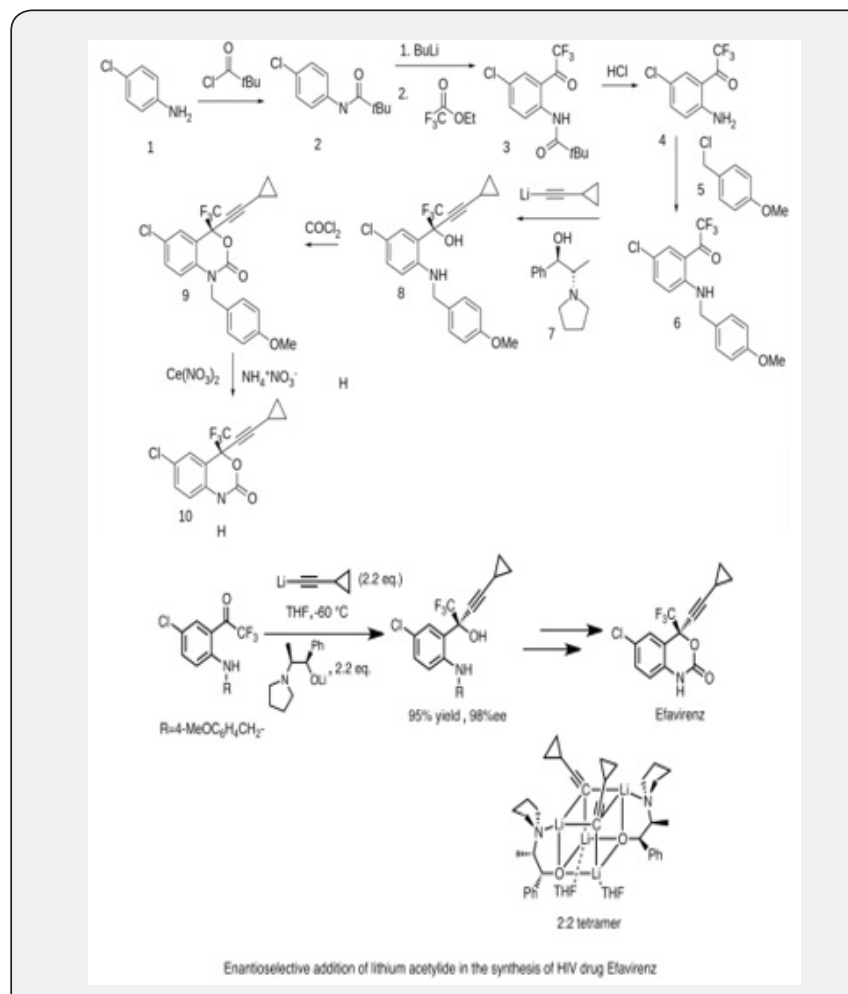

Figure 2: Enantioselective addition of lithium acetylide in the synthesis of HIV drug Efavirenz.

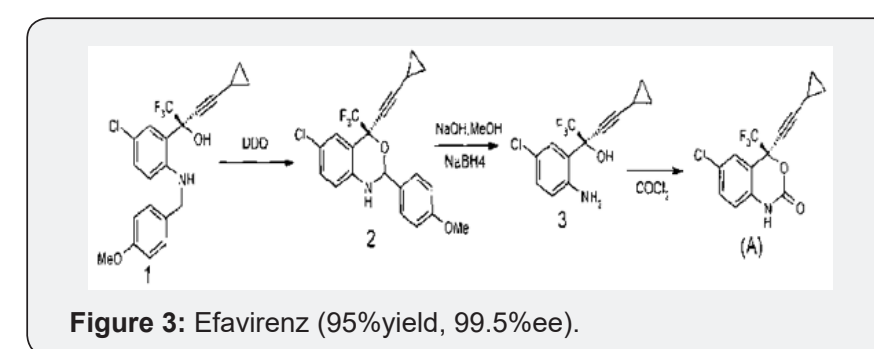

Additionally, the asymmetric synthesis of an enantiomeric benzoxazine by a highly enantioselective acetylide addition and cyclization sequence has been described by Thompson, et al., Tetrahedron Letters 1995, 36, 8937-8940, as well as the PCT publication, WO 96/37457, which published on November 28, 1996.Additionally, several applications have been filed which disclose various aspects of the synthesis of(-)-6-chloro4-cyclopropylethynyl-4-trifluoromethyl-1,4-dihydro-2H-3,1benzoxazin-2-one including: 1) a process for making the chiral alcohol, U.S.S.N. 60/035,462, filed 14 January 1997; 2) the chiral additive, U.S.S.N. 60/034,926, filed 10 January 1997; 3) the 
cyclization reaction, U.S.S.N. 60/037,059, filed 12 February 1997; and the anti-solvent crystallization procedure, U.S.S.N. 60/037,385 filed 5 February 1997 and .S.S.N. 60/042,807 filed 8 April 1997 (Figures 2 \& 3) [8].

Efavirenz has been obtained by two related ways: 1) The acylation of 4-chloroaniline (I) with pivaloyl chloride (II) by means of $\mathrm{Na} 2 \mathrm{CO} 3$ in toluene gives the expected anilide (III), which is acylated with ethyl trifluoroacetate by means of butyllithium in THF yielding, after hydrolysis with $\mathrm{HCl}, 2$ '-amino5'-chloro-2,2,2-trifluoroacetophenone (IV). The benzylation of (IV) with 4-methoxybenzyl chloride (V) in basic alumina affords the protected acetophenone (VI), which is regioselectively condensed with cyclopropylacetylene (VII) [obtained by cyclization of 5-chloro-1-pentyne (VIII) by means of butyllithium in cyclohexane] by means of butyllithium in THF in the presence of (1R,2S)-1-phenyl-2-(1-pyrrolidinyl)-1-propanol (IX) giving the (S)-isomer of the tertiary alcohol $(\mathrm{X})$ exclusively. The cyclization of $(\mathrm{X})$ with phosgene and triethylamine or $\mathrm{K} 2 \mathrm{CO} 3$ in toluene/ THF yields the benzoxazinone (XI), which is finally deprotected with ceric ammonium nitrate in acetonitrile/water. 2) The condensation of 2 '-amino-5'-chloro-2,2,2-trifluoroacetophenone (IV) with cyclopropylacetylene (VIII) by means of butyllithium or ethylmagnesium bromide in THF gives (?-2-(2-amino-5chlorophenyl)-4-cyclopropyl-1,1,1-trifluoro-3-butyn-2-ol (XII). The cyclization of (XII) with carbonyldiimidazole (XIII) in hot THF yields the racemic benzoxazinone (XIV). Compound (XIV) is submitted to optical resolution by condensation with (S)-()-camphanoyl chloride by means of dimethyl aminopyridine (DMAP) in dichloromethane to give the acyl derivative (XVI) as a diastereomeric mixture that is resolved by crystallization and finally decomposed with $\mathrm{HCl}$ in ethanol or butanol [9].

Corley EG, Thompson AS, Huntington MF, Grabowski EJJ, use of an ephedrine alkoxide to mediate enantioselective addition of an acetylide to a prochiral ketone: Asymmetric synthesis of the reverse transcriptase inhibitor L-743,726 Tetrahedron Lett1995,36,(49):8937-40 [10].

\section{EP 1332757 A1}

When a commercial market already exists for the RMs used in synthesizing an API, their cost can be rather modest. When RMs used in synthesizing an API have no other commercial use, however, they can contribute very substantially to API cost. With a continued growth of volume demand, improved chemistry and competition from multiple suppliers, however, the cost of API RMs can greatly decrease over time. The inhibitor of HIV-1 RT, EFV, provides an illustration of this situation. Cyclopropylacetylene (CPA) is an RM for the synthesis of EFV (Figure 4). During clinical trials, when the demand for CPA was only a few metric tons, this material was produced at a price of USD $800-1,350 / \mathrm{kg}$. When the drug was first approved in 1998, and demand for CPA was about 50 metric tons per year, the price of CPA had fallen to USD350/kg. Today, with global demand for EFV at greater than 1,000 metric tons/year, CPA can be purchased for about USD50-60/kg. In the earliest stages of production, nearly $1 \mathrm{~kg}$ of CPA was needed to produce a kilogram of EFV. Current production processes are more efficient; roughly $3 \mathrm{~kg}$ of EFV is now produced for each $1 \mathrm{~kg}$ of CPA used. From this it can be roughly estimated that the contribution of CPA to the cost of EFV API production has fallen from as high as USD425/kg to about USD17-20/kg today [11].

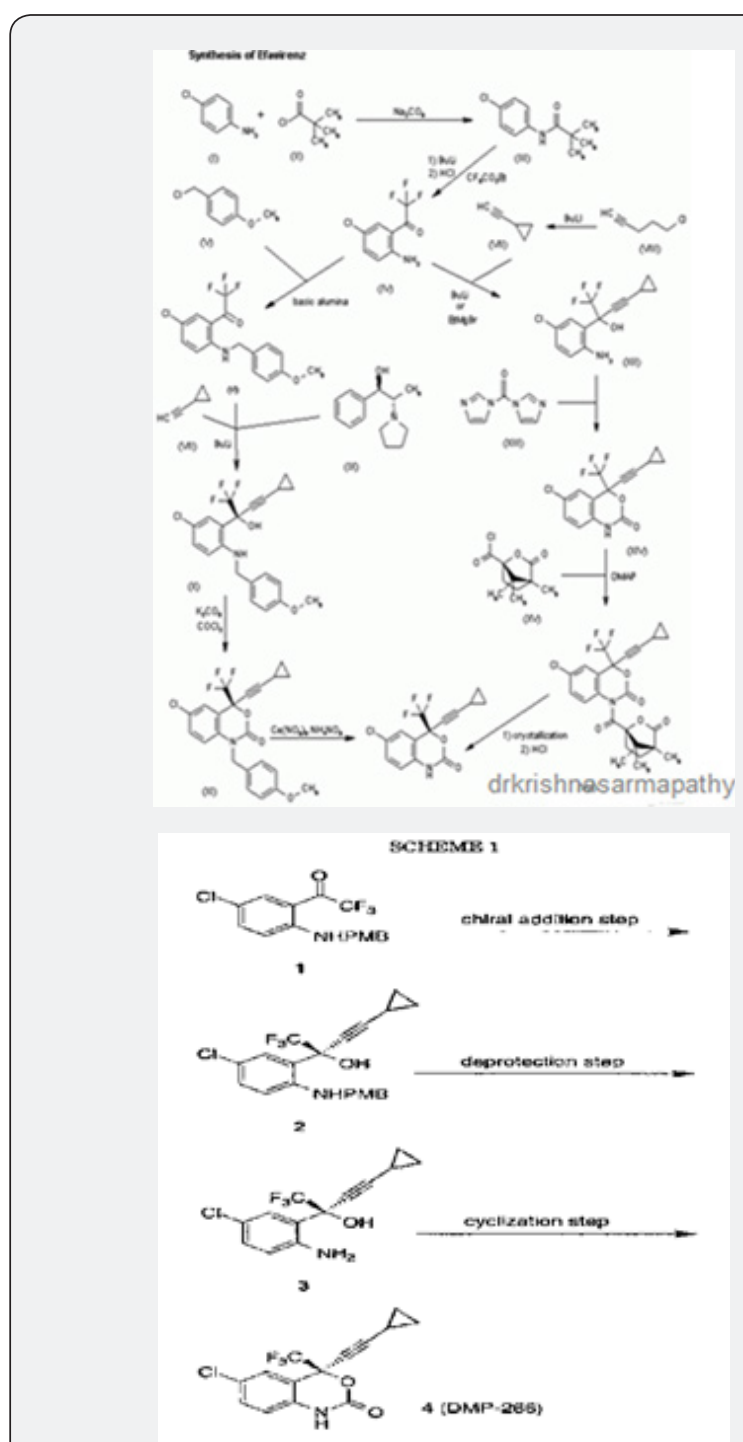

Figure 4: Tetrahedron Lett (1995)36(49): 8937-40.

The most recent chemistry for asymmetric alkylation of manufacturing EFV uses inexpensive, safe reagents and processing at ambient temperature to reach EFV pricing that would have been thought impossible when the drug was launched by Dupont Pharmaceuticals in 1998Biao J, Yugui S. inventors; Shanghai Institute of Organic Chemistry, Chinese Academy of Sciences, assignee. Amino alcohol ligand and its use in preparation of chiral propargylic tertiary alcohols and tertiary amines via enantioselective addition reaction. US Patent 7,439,400. 2008 October 21 [12].

Bollu RB, Ketavarapu NR, Indukuri VSK, Gorantla SR, Chava S. inventors; Laurus Labs Private Limited, assignee. Efficient process to induce enantioselectivity in procarbonyl compounds. US Patent 
Application 2012/0264933 A1. 2012 October 18.FPPs for adult ART are usually capsules or tablets. A general rule-of-thumb is that an FPP as a conventional, solid oral dosage formulation costs about 33-40\% more than the corresponding API in a competitive market (Figure 4a). It has been widely quoted, conversely, that APIs contribute about $60-80 \%$ of the cost of an FPP. The API contribution to FPP cost increases with the complexity of synthesis and API cost per kilogram. Although marketing is a substantial incremental cost for originator pharmaceutical companies, generic producers do not incur high marketing costs for ART [13].

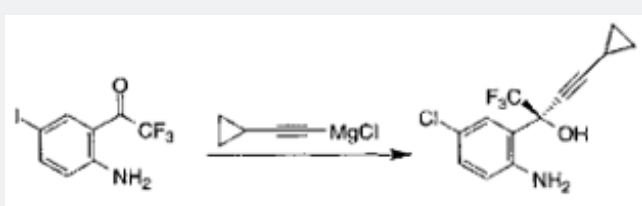

Figure 4a:

To a solution of trifluoroethanol and (IR, 2S)-N-pyrrolidinyl norephedrine in THF (9L) under nitrogen is added a solution of diethylzinc in hexane at $0^{\circ} \mathrm{C}$ slowly enough to keep the temperature below $30^{\circ} \mathrm{C}$. The mixture is stirred at room temperature for $0.5 \sim 1 \mathrm{~h}$ In another dry flask a solution of chloromagnesium cyclopropyl acetylide is prepared as follows: To neat cyclopropyl acetylene at $0^{\circ} \mathrm{C}$ is added a solution of rc-butylmagnesium chloride slowly enough to keep the internal temperature $<30^{\circ} \mathrm{C}$. The solution is stirred at $0^{\circ} \mathrm{C}$ for $\sim 40 \mathrm{~min}$ and transferred to the zinc reagent via cannula with $0.36 \mathrm{~L}$ of THF as a wash. The mixture is cooled to $-10^{\circ} \mathrm{C}$ and ketoaniline la is added. The mixture is stirred at -2 to $-8^{\circ} \mathrm{C}$ for $35 \mathrm{~h}$, warmed to room temperature, stirred for $3 \mathrm{~h}$, and quenched with $30 \%$ potassium carbonate over $1.5 \mathrm{~h}$. The mixture is stirred for $4 \mathrm{~h}$ and the solid is removed by filtration and washed with THF ( 2 cake volume). The wet solid still contains $-18 \mathrm{wt} \%$ of pyrrolidinyl norephedrine and is saved for further study. The filtrate and wash are combined and treated with $30 \%$ citric acid. The two layers are separated. The organic layer is washed with water $(1.5 \mathrm{~L})$. The combined aqueous layers are extracted with $2.5 \mathrm{~L}$ of toluene and saved for norephedrine recovery. The toluene extract is combined with the organic solution and is concentrated to $\sim 2.5 \mathrm{~L}$. Toluene is continuously feeded and distilled till THF is not detectable by GC. The final volume is controlled at $3.9 \mathrm{~L}$. Heptane $(5.2 \mathrm{~L})$ is added over $1 \mathrm{~h}$. The slurry is cooled to $0^{\circ} \mathrm{C}$, aged for $1 \mathrm{~h}$, and filtered. The solid is washed with heptane $(2$ cake volume) and dried to give $1.234 \mathrm{Kg}$ (95.2\% yield) of amino alcohol 3 as a white crystalline. The material is $99.8 \mathrm{~A} \%$ pure and $99.3 \%$ ee [14].

To a three necked round bottom flask, equipped with a mechanical stirrer, nitrogen line, and thermocouple, was charged the solid amino alcohol 3, MTBE (500 L), and aqueous KHCO3 (45 $\mathrm{g}$ in $654 \mathrm{~mL} \mathrm{H2O}$ ). Solid 4-nitrophenyl chloroformate was added, in 4 batches, at $25^{\circ} \mathrm{C}$. During the addition the solution $\mathrm{pH}$ was monitored. The $\mathrm{pH}$ was maintained between 8.5 and 4 during the reaction and ended up at 8.0 . The mixture was stirred at $20-25^{\circ} \mathrm{C}$ for two hours. Aqueous $\mathrm{KOH}(2 \mathrm{~N})$ was added over 20 minutes, until the $\mathrm{pH}$ of the aqueous layer reached 11.0.

The layers were separated, and $500 \mathrm{~mL}$ brine was added to the MTBE layer. $0.1 \mathrm{~N}$ Acetic acid was added until the $\mathrm{pH}$ was 6-7. The layers were separated, and the organic phase was washed with brine $(500 \mathrm{~mL})$. At this point the mixture was solvent switched to EtOH/IPA and crystallized as recited in Examples 5 and 6. To a three necked round bottom flask, equipped with a mechanical stirrer, nitrogen line, and thermocouple, was charged the solid amino alcohol 3a, toluene $(500 \mathrm{~mL})$, and aqueous KHCO3 $(86.5 \mathrm{~g}$ in $500 \mathrm{~L} \mathrm{H} 20$ ). Phosgene solution in toulene was added at $25^{\circ} \mathrm{C}$, and the mixture was stirred at $20-25^{\circ} \mathrm{C}$ for two hours. The layers were separated, and the organic phase was washed with brine (500 $\mathrm{mL}$ ). At this point the mixture was solvent switched to EtOH/IPA and crystallized as recited in Examples 5 and 6.

To a three necked round bottom flask, equipped with a mechanical stirrer, nitrogen line, and thermocouple, was charged the solid amino alcohol 3a, MTBE (500 mL), and aqueous KHCO3 ( $86.5 \mathrm{~g}$ in $500 \mathrm{~mL} \mathrm{H} 20$ ). Phosgene gas was slowly passed into the solution at $25^{\circ} \mathrm{C}$, until the reaction was complete. The layers were separated, and the organic phase was washed with brine $(500 \mathrm{~mL})$. At this point the mixture was solvent switched to EtOH/IPA and crystallized as recited in Examples 5 and 6.

Crystallization of efavirenz from 30\% 2-Propanol in Water using a ratio of $15 \mathrm{ml}$ solvent per gram efavirenz Using Controlled Anti-Solvent Addition on a 400g Scale. 400 g. of efavirenz starting material is dissolved in 1.8L of 2-propanol. The solution is filtered to remove extraneous matter. $1.95 \mathrm{~L}$ of deionized (DI) water is added to the solution over 30 to 60 minutes. $10 \mathrm{~g}$. to $20 \mathrm{~g}$. of efavirenz seed (Form II wetcake) is added to the solution. The seed bed is aged for 1 hour. The use of Intermig agitators is preferred to mix the slurry. If required (by the presence of extremely long crystals or a thick slurry), the slurry is wet milled for 15-60 seconds. $2.25 \mathrm{~L}$ of DI water is added to the slurry over 4 to 6 hours. If required (by the presence of extremely long crystals or a thick slurry), the slurry is wet- milled for $15-60$ seconds during the addition. The slurry is aged for 2 to 16 hours until the product concentration in the supernatant remains constant. The slurry is filtered to isolate a crystalline wet cake. The wet cake is washed with 1 to 2 bed volumes of $30 \%$ 2-propanol in water and then twice with 1 bed volume of DI water each. The washed wet cake is dried under vacuum at $50^{\circ} \mathrm{C}[15]$.

Crystallization of efavirenz from 30\% 2-Propanol in Water using a ratio of $15 \mathrm{ml}$ solvent per gram efavirenz Using a SemiContinuous Process on a 400 g Scale. 400 g. of efavirenz starting material is dissolved in $1.8 \mathrm{~L}$ of 2- propanol. A heel slurry is produced by mixing $20 \mathrm{~g}$. of Form II efavirenz in $0.3 \mathrm{~L} \mathrm{of} 30 \% \mathrm{v} / \mathrm{v}$ ) 2-propanol in water or retaining part of a slurry from a previous crystallization in the crystallizer. The dissolved batch and $4.2 \mathrm{~L}$ of DI water are simultaneously charged to the heel slurry at constant rates over 6 hours to maintain a constant solvent composition in 
the crystallizer. Use of Intermit agitators during the crystallization is preferred. During this addition the slurry is wet milled when the crystal lengths become excessively long, or the slurry becomes too thick. The slurry is aged for 2 to 16 hours until the product concentration in the supernatant remains constant. The slurry is filtered to isolate a crystalline wet cake. The wet cake is washed with 1 to 2 bed volumes of 30\% 2-propanol in water and then twice with 1 bed volume of DI water each. The washed wet cake is dried under vacuum at $50^{\circ} \mathrm{C}$ [16] Example 7.

A solution of diethyl zinc in hexane was added to a solution of trifluoroethanol (429.5 g, 4.29' mol) and (IR, 2S)-N-pyrrolidinyl norephedrine $(1.35 \mathrm{~kg}, 6.58 \mathrm{~mol})$ in THF ( $9 \mathrm{~L})$, under nitrogen, at $0^{\circ} \mathrm{C}$. The resulting mixture was stirred at room temperature for approx. $30 \mathrm{~min}$. In another dry flask a solution of chloromagnesiumcyclopropylacetylide was prepared as follows. To a solution of $\mathrm{n}$ - butyl magnesium chloride in THF (2M, 2.68L, 5.37mol) was added neat cyclopropyl acetylene at $0^{\circ} \mathrm{C}$ keeping the temperature $<25^{\circ} \mathrm{C}$. The solution was stirred at $0^{\circ} \mathrm{C}$ for $1 \sim 2 \mathrm{~h}$. The solution of chloromagnesium cyclopropylacetylide was then warmed to room temperature and was transferred into the zinc reagent via cannula over 5 min followed by vessel rinse with $0.36 \mathrm{~L}$ of THF. The resulting mixture was aged at $\sim 30^{\circ} \mathrm{C}$ for $0.5 \mathrm{~h}$ and was then cooled to $20^{\circ} \mathrm{C}$. The ketoaniline $1(1.00 \mathrm{~kg}, 4.47 \mathrm{~mol})$ was added in one portion as a solid, and the resulting mixture was stirred at 20 $28^{\circ} \mathrm{C}$ for $3 \mathrm{~h}$. The reaction was quenched with $30 \%$ aq. potassium carbonate (1.2L) and aged for $1 \mathrm{~h}$. The solid waste was filtered and the cake was washed with THF ( 3 cake volumes). The filtrate and wash were combined, and solvent switched to IP Ac [17].

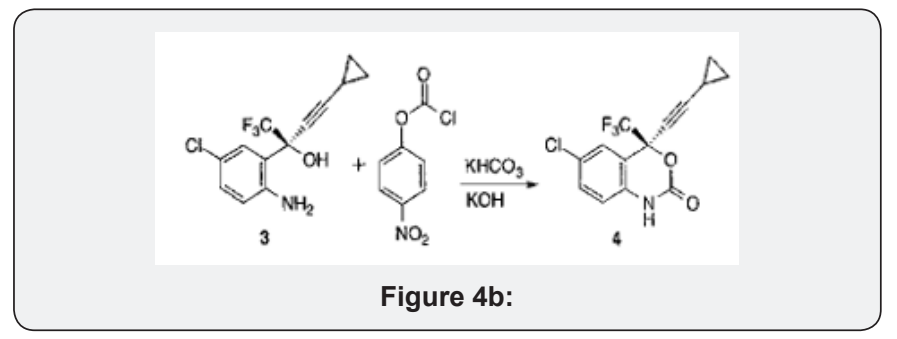

The IPAc solution of product 3 and pyrrolidinyl norephedrine was washed with citric acid (3.5L) and with water $(1.5 \mathrm{~L})$. The combined aqueous layers were extracted with IPAc (2L) and saved for norephedrine recovery. To the combined organic layers was added $12 \mathrm{~N} \mathrm{HC1} \mathrm{(405mL,} \mathrm{4.88mol),} \mathrm{to} \mathrm{form} \mathrm{a} \mathrm{thin} \mathrm{slurry} \mathrm{of} \mathrm{the}$ amino alcohol-HC1 salt. The mixture was aged for $30 \mathrm{~min}$ at $25^{\circ} \mathrm{C}$ and was then dried azeotropically. The slurry was aged at $25^{\circ} \mathrm{C}$ for $30 \mathrm{~min}$ and filtered. The cake was washed with $2.5 \mathrm{~L}$ of IPAc and dried at $25^{\circ} \mathrm{C}$ under vacuum/nitrogen for $24 \mathrm{~h}$ to give $1.76 \mathrm{~kg}$ of the wet HC1 salt. The salt was dissolved in a mixture of MTBE (6L) and aq $\mathrm{Na} 2 \mathrm{CO} 3$ (1.18 kg in $6.25 \mathrm{~L}$ water). The layers were separated, and the organic layer was washed with $1.25 \mathrm{~L}$ of water. The organic layer was then solvent switched into toluene. Heptane (5 L) was added over $1 \mathrm{~h}$ at $25^{\circ} \mathrm{C}$. The slurry was cooled to $0^{\circ} \mathrm{C}$, aged for $1 \mathrm{~h}$, and filtered. The solid was washed with heptane $(2$ cake volumes) and was dried to give $1.166 \mathrm{~kg}$ ( $90 \%$ overall yield) of amino alcohol 3 as a white crystalline solid figure 4 (b).

\section{Norephedrine Recovery}

The aqueous solution was basified to pH13 using 50\% as $\mathrm{NaOH}$ and extracted with heptane (2L). The heptane solution was washed with water (1L) and concentrated to remove residual IPAc and water. The final volume was adjusted to about $3 \mathrm{~L}$. The heptane solution was cooled to $-20^{\circ} \mathrm{C}$, aged for $2 \mathrm{~h}$, and filtered. The solid was washed with cold heptane (1 cake volume) and dried to give $1.269 \mathrm{~kg}$ solid ( $94 \%$ recovery).

Intermediate preparation: The key intermediate of efavirenz: (S)-1-(2-amino-5-chlorophenyl)-1-trifluoromethyl-3cyclopropyl-2-propyne-1-ol (1) was prepared. P-Chloroaniline (2) reacted with pivaloyl chloride to give $\mathrm{N}$-(4-chlorophenyl)2,2-dimethylpropanamide (4). After a Friedel-Crafts acylation of compound 4 catalyzed by aluminum trichloride, and a hydrolysis under acidic conditions, 4-chloro-2-(trifluoroacetyl)aniline hydrochloride (5) was obtained. In this step, the hazardous reagent n-butyllithium was abolished. Compound 5 was basified to afford 4-chloro-2-(trifluoroacetyl)aniline (6). Then compound 6 reacted with chloromagnesium cyclopropylacetylide under the catalytic system formed by zinc chloride and (1R,2S)-1-phenyl-2(1-pyrrolidinyl)-1-propanol (7) and a small amount of purified 1 to obtain the target compound 1 by asymmetric autocatalysis with an overall yield of $69.5 \%$ (based on 2). In the last step, zinc chloride was used instead of diethylzinc, the yield was increased from $79 \%$ to $85.6 \%$. And ligand 7 was recovered with a recovery rate of $98 \%$, which could reduce the cost successfully. This improved synthetic route has mild reaction conditions and the yield of each step was excellent Figure 4(c).

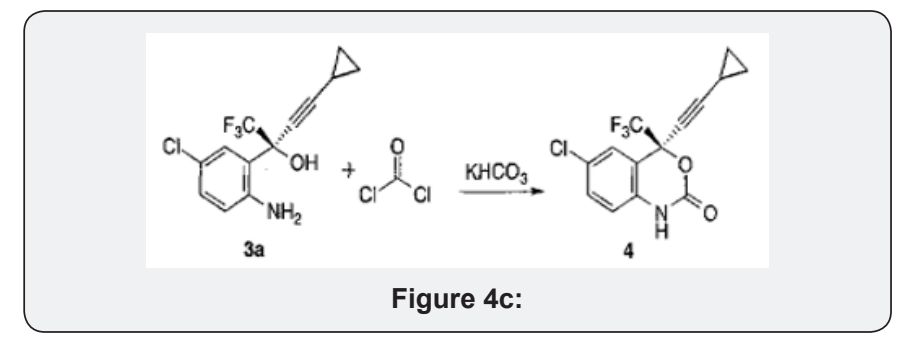

Materials and Methods

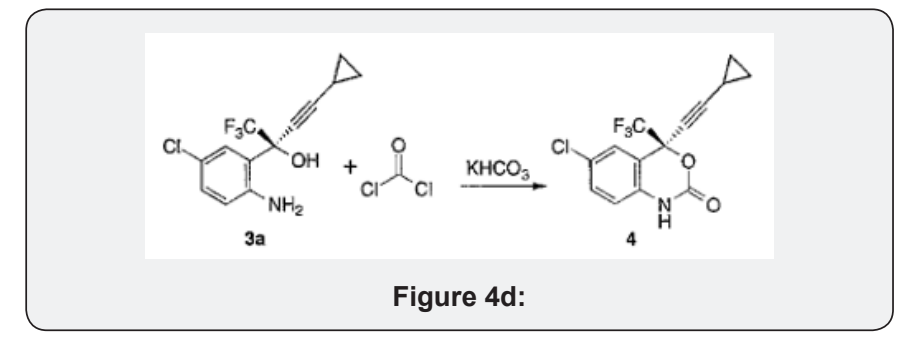

General procedure- $1 \mathrm{H}$ NMR spectra were recorded on a Gemini $300 \mathrm{MHz}$ FT NMR spectrometer; the chemical shifts are reported in $\delta \mathrm{ppm}$ relative to TMS. The IR spectra were recorded in the solid state as $\mathrm{KBr}$ dispersion using Perkin Elmer Spectrophotometer. The mass spectra were recorded on Shimadzu LCMS-QP8000, LC-MS and AB-4000 Q-trap LC-MS/MS Figure 4(d).

A solution of (S)-5-chloro- $\alpha$-(cyclopropylethynyl)-2-amino$\alpha$-(trifluoroethyl)benzene methanol (I) (10 gm, 0.034mole) and 
urea (2.48 gm, 0.0414 mole in toluene are refluxed in the presence of para-tolunesulphonic acid (PTSA) $(0.31 \mathrm{gm}, 0.0006 \mathrm{~mole})$ for 20 hrs. After completion of the reaction as monitored by Thin Layer Chromatorgraphy (TLC), the reaction mixture was cooled to room temperature and then $30 \mathrm{ml}$ of water was added. The obtained aqueous layer was extracted with toluene. The combined toluene layers were concentrated under reduced pressure. The obtained residue was cooled to room temperature and $30 \mathrm{ml}$ of methanol was added and stirred. Methanol was distilled of to remove the toluene traces. Again, methanol was added to the residue and cooled to $10-15^{\circ} \mathrm{C}$ Figure $4(\mathrm{e})$.

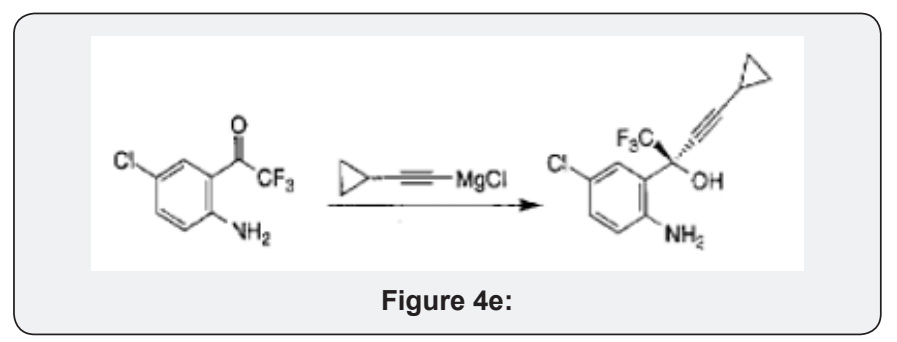

To this residue water was added at $10-15^{\circ} \mathrm{C}$ and stirred for 3 hrs. The obtained white solid was re-crystallized in toluene and heptane mixture to get 9.2gms of (4S)-6-chloro4-(cyclopropylethynyl)-1,4-dihydro-4-(trifluoromethyl)-2H3,1-benzoxazin-2-one (II) (Efavirenz). 1H NMR (300MHz in DMCO-d6): $\delta$ 0.782-0.815 (m, 2H), 0.908-0.956 (m,2H), 1.557$1.646(\mathrm{~m}, 1 \mathrm{H}$, cyclopropyl), 6.98-7.013(d, 1H), 7.45(s, 1H), 7.55$7.58(\mathrm{dd}, 1 \mathrm{H}), 11.11(\mathrm{~s}, 1 \mathrm{H})$.

\section{Mass}

$\mathrm{M} / \mathrm{z} ; 314.2$, in negative ion mode. Yield: $85 \%$, MR: $136-139^{\circ} \mathrm{C}$, SOR $-92.8^{\circ}$ (c 0.3 in $\mathrm{MeOH}$ ) Chemicals and reagents Ethanol was used for the quantification of efavirenz which was procured from Sigma Aldrich. EFA film coated tablet of strength $600 \mathrm{mg}$ Sustiva (Bristo-Myers Squibb-Germany) and Efavir (Cipla Ltd-India) were procured from the market. The pure sample of efavirenz for the research work was procured from Shasun Pharmaceuticals Ltd, Pondicherry. Hydrochloric acid, sodium hydroxide, and - naphthol were purchased from Sigma Aldrich. All the chemicals and reagents for the development of new analytical method to estimate efavirenz was of analytical grade. Preparation of - naphthol reagent Accurately $1 \mathrm{~g}$ of - naphthol was weighed and transferred to $100 \mathrm{ml}$ volumetric flask. To it $30 \mathrm{ml}$ of $0.1 \mathrm{~N} \mathrm{NaOH}$ was added and shacked such that - naphthol gets completely dissolved in $\mathrm{NaOH}$. Make up the volume to $100 \mathrm{ml}$ with $0.1 \mathrm{~N} \mathrm{NaOH}$. Preparation of Efavirenz standard solutions $100 \mathrm{mg}$ of the drug was weighed and transferred in to $100 \mathrm{ml}$ volumetric flask, to it ethanol was added, and volume was made up to $100 \mathrm{ml}$ with ethanol. From this $10 \mathrm{ml}$ was transferred to $100 \mathrm{ml}$ volumetric flask and volume was made up to $100 \mathrm{ml}$ with ethanol such that the solution gives the concentration of 100/. Preparation of reagent blank. The reagent blank was prepared in the same manner as discussed, omitting the standard drug solution. Procedure for the analysis of tablet formulation Twenty tablets of Efavirenz $(600 \mathrm{mg})$ and Sustiva were purchased from local market. Accurately weighed and finely powdered. The weight of the tablet equivalent to $100 \mathrm{mg}$ from each brand was accurately weighed and extracted with ethanol. The yellow colored complex (Scheme-1) having final concentration of $100 \mathrm{mg} / \mathrm{ml}$ of each brand was prepared. The absorbance of the solutions was measured at $561 \mathrm{~nm}$ using reagent blank Figure (5).

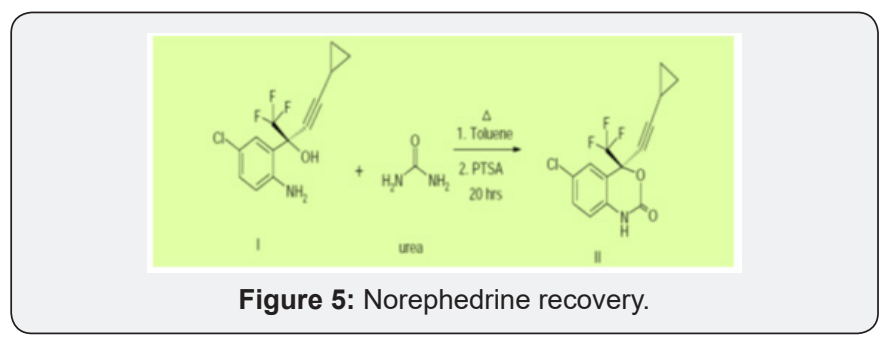

Results and Discussion

Table 1: To a solution of trifluoroethanol and (IR, 2S)-N-pyrrolidinyl norephedrine.

\begin{tabular}{|c|c|c|c|}
\hline Materials & Amount & Mol & MW \\
\hline Ketone $1 \mathrm{a}$ & $1.00 \mathrm{Kg} \mathrm{g}$ & 4.47 & 223.58 \\
\hline $\begin{array}{l}(1 \mathrm{R}, 2 \mathrm{~S}) \text { - } \mathrm{N} \text { - pyrrolidinyl norephed- } \\
\text { rine }\end{array}$ & $1.35 \mathrm{~kg}$ & 6.58 & \\
\hline cyclopropylacettylene & $361.9 \mathrm{~g}$ & 5.47 & \\
\hline n- BuMgcl (2.0 M in THF) & $2.68 \mathrm{~L}$ & 5.37 & \\
\hline 2,2,2-trifluroethonol (99\%) & $429.5 \mathrm{~g}$ & 4.29 & \\
\hline ZnEt2(0.892 M in hexane) & $6.02 \mathrm{~L}$ & 5.37 & \\
\hline THF & $9.36 \mathrm{~L}$ & & \\
\hline $30 \% \mathrm{k}_{2} \mathrm{Co}_{3}$ & $550 \mathrm{ml}$ & & \\
\hline $30 \%$ ctiric acid & $2.0 \mathrm{~L}$ & & \\
\hline $\begin{array}{l}\text { toluene (for crystalization, } 2 \mathrm{~mL} / \mathrm{g} \\
\text { of } 4\end{array}$ & $2.6 \mathrm{~L}$ & & \\
\hline $\begin{array}{l}\text { Heptane(for crystalization ,4 mL } \\
\text { /g of } 4\end{array}$ & $5.2 \mathrm{~L}$ & & \\
\hline
\end{tabular}

Selection of analytical wavelength: Appropriate dilutions were prepared for drug from the standard stock solution and the solutions were scanned in the wavelength range of 400 $800 \mathrm{~nm}$. Absorption maxima were found to be $561 \mathrm{~nm}$ which was selected as wavelength of analytical measurement for this method. Calibration curve Appropriate volume of aliquots from standard Efavirenz stock solution II were transferred to different volumetric flasks of $10 \mathrm{ml}$ capacity. To all the volumetric flasks $1 \mathrm{ml}$ of $1 \%$ sodium nitrite, $1 \mathrm{ml}$ of $\mathrm{HCl}$ and finally $h$ was added. The volume was adjusted to the mark with ethanol to obtain concentrations of $10,12,14,16,18$ and 20 /. Absorbance of each solution blank was measured at $561 \mathrm{~nm}$ and the graph of absorbance against concentration was plotted and is shown in figure 1. The regression equation and correlation coefficient were determined. The method was validated according to International Conference on Harmonization guidelines for validation of analytical procedures $[9,10,11]$. Efavirenz has the absorbance maxima at $561 \mathrm{~nm}$ for the first order derivative visible-Spectrophotometric method. The optical characteristics such as Beer's limits, Limit of detection and Limit of quantification etc., in each method were calculated and 


\section{Organic and Medicinal Chemistry International Journal}

the results were presented in Table 1 respectively. The regression characteristics like slope (b), intercept (a), and correlation coefficient (R2) using the method of least squares were calculated and presented in Table 1 respectively. The results showed that the methods have reasonable precise. The validation parameters like Precision and Accuracy results were presented in Tables 2 \& 3 for Visible Spectrophotometric method. There was no interference of excipients in recovery study of the method. From results, the method found applicable for both bulk and pharmaceutical dosage for the estimation of Efavirenz. Recovery studies. The recovery studies were carried out at three different level i.e. 80,100 and $120 \%$. It was performed by adding known amount of standard drug solutions of Efavirenz to preanalysed tablets solutions (Figure 6). The resulting solutions were then reanalyzed by proposed methods. The results of recovery studies are shown in Tables 4 \& 5 .

Table 2: The material is $99.8 \mathrm{~A} \%$ pure and $99.3 \%$ ee.

\begin{tabular}{|c|c|c|c|c|c|}
\hline & FW & g & mL & m mol & equiv \\
\hline amino alcohol 3 & 289 & 100 & & 346 & 1 \\
\hline $\begin{array}{c}\text { 4- nitrophenyl } \\
\text { chloroformate }\end{array}$ & 201.6 & 73.2 & & 363 & 1.05 \\
\hline $\mathrm{KHCO}_{3}$ & & & & & \\
\hline $2 \mathrm{~N} \mathrm{KOH}$ & 56 & & 346 & 692 & 2 \\
\hline $\mathrm{H}_{2} \mathrm{O}$ & & & 654 & & \\
\hline MTBE & & & 500 & & \\
\hline
\end{tabular}

Table 3: To a three necked round bottom flask, equipped with a mechanical stirrer.

\begin{tabular}{|c|c|c|c|c|c|}
\hline & FW & g & mL & m mol & equiv \\
\hline amino alcohol 3a & 289 & 100 & & 346 & 1 \\
\hline $\begin{array}{c}\text { Phosgene(20 wt\% } \\
\text { in tolunce) }\end{array}$ & 99 & 41 & 216 & 415 & 1.2 \\
\hline $\mathrm{KHCO}_{3}$ & 100 & 86.5 & & 865 & 2.5 \\
\hline $\mathrm{H}_{2} \mathrm{O}$ & & & 500 & & \\
\hline Toluene & & & 500 & & \\
\hline
\end{tabular}

Table 4: To a three necked round bottom flask, equipped with a mechanical stirrer.

\begin{tabular}{|c|c|c|c|c|c|}
\hline & FW & g & mL & m mol & equiv \\
\hline amino alcohol 3a & 289 & 100 & & 346 & 1 \\
\hline $\begin{array}{c}\text { Phosgene(20 wt\% in } \\
\text { tolunce) }\end{array}$ & 99 & & & & \\
\hline $\mathrm{KHCO}_{3}$ & 100 & 86.5 & & 865 & 2.5 \\
\hline $\mathrm{H}_{2} \mathrm{O}$ & & & 500 & & \\
\hline Toluene & & & 500 & & \\
\hline
\end{tabular}

Table 5: A solution of diethyl zinc in hexane was added to a solution of trifluoroethanol.

\begin{tabular}{|c|c|c|c|}
\hline Materials & Amount & Mol & MW \\
\hline Ketone 1a & $1.00 \mathrm{Kg}$ & 4.47 & 223.58 \\
\hline $\begin{array}{c}(1 \mathrm{R}, 2 \mathrm{~S}) \\
-\begin{array}{c}\text { N- pyrrolidinyl nore- } \\
\text { phedrine }\end{array}\end{array}$ & $1.35 \mathrm{~kg}$ & 6.58 & 205.3 \\
\hline
\end{tabular}

\begin{tabular}{|c|c|c|c|}
\hline cyclopropylacettylene & $361.9 \mathrm{~g}$ & 5.47 & 66.1 \\
\hline $\mathrm{n}$ - BuMgcl (2.0 M in THF) & $2.68 \mathrm{~L}$ & 5.37 & \\
\hline $2,2,2$-trifluroethonol (99\%) & $429.5 \mathrm{~g}$ & 4.29 & 100.04 \\
\hline $\mathrm{ZnEt}_{2}(0.892 \mathrm{M}$ in hexane) & $6.02 \mathrm{~L}$ & 5.37 & \\
\hline $\mathrm{THF}$ & $9.36 \mathrm{~L}$ & & \\
\hline $30 \% \mathrm{k}_{2} \mathrm{Co}_{3}$ & $1.2 \mathrm{~L}$ & & \\
\hline $30 \%$ citric acid & $3.5 \mathrm{~L}$ & & \\
\hline Heptane & $12 \mathrm{~L}$ & & \\
\hline Isopropyl acetone (IPAc) & $40 \mathrm{~L}$ & & \\
\hline $12 \mathrm{~N} \mathrm{HCl}$ & $405 \mathrm{~mL}$ & 4.88 & \\
\hline tert-butyl methyl ether (MTBE) & $6 \mathrm{~L}$ & & \\
\hline toluene & $6.25 \mathrm{~L}$ & & \\
\hline $\mathrm{Na}_{2} \mathrm{Co}_{3}$ & $1.2 \mathrm{Kg}$ & 11.25 & \\
\hline
\end{tabular}

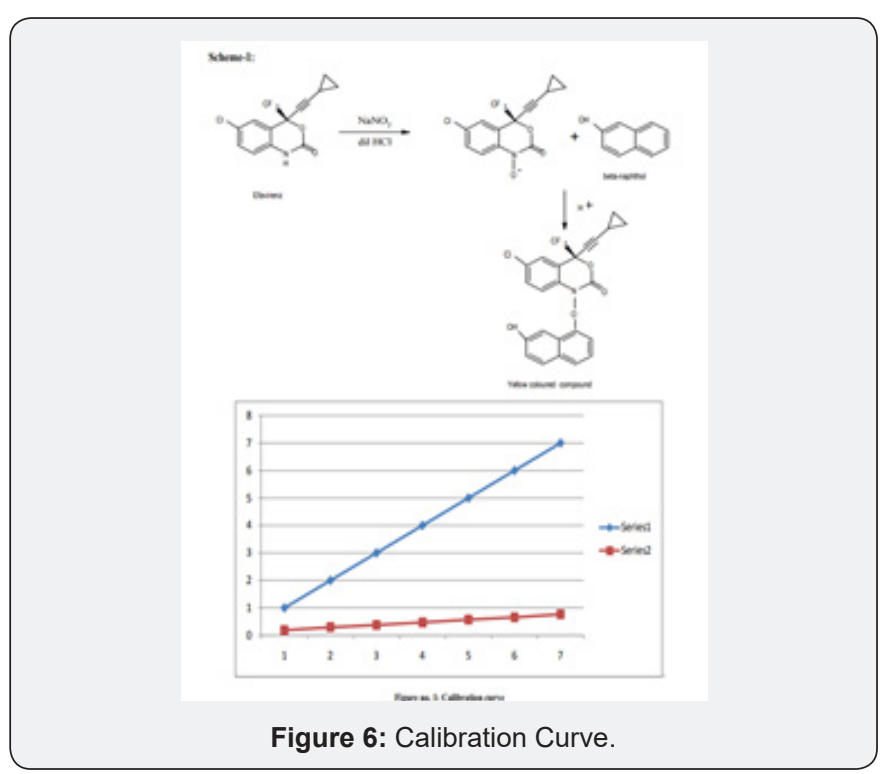

\section{Conclusion}

After patent evaluation finally concluded that efavirenz US granted patent John Doney, "Amorphous efavirenz and the production thereof." U.S. Patent US20070026073, issued February 01, 2007 ,process patent W01999061026 both patents selected for process for preparation of efavirenz. We have surprisingly found that compound of Efavirenz can be prepared in good yield and high purity by Cyclisation of compound of (S)-2-(2amino-5-chlorophenyl)-4-cyclopropyl-1,1,1-trifluorobut-3-yn2 -ol with urea as shown in the above scheme. This cyclization of compound of (S)-2-(2-amino-5-chlorophenyl)-4-cyclopropyl-1, 1, 1-trifluorobut-3-yn-2-ol is affected in a suitable reaction media which includes aromatic hydrocarbons, aqueous alcohols, ketones . more preferably toluene. Optionally, the above Cyclisation is conducted in presence of an acid. The suitableacids may include mineral acids for example hydrochloric acid, sulfuric acids etc. organic acids like ptoluenesulphonicacid, acetic acid and trifluoro acetic acid etc. The cyclization is conveniently affected at elevated temperatures, most conveniently at reflux temperature of the reaction mixture. We have described a novel synthesis for the 


\section{Organic and Medicinal Chemistry International Journal}

preparation of Efavirenz employing simple reaction condition and simple substrate. The synthesis is economically viable and is capable of Industrial production. Also, a colorimetric method for quantifying Efavirenz in bulk drug and formulation has been developed and validated. The method is selective, precise, accurate and linear over the concentration range studied. The method is simple and suitable for the determination of Efavirenz in bulk drug and in formulation without interference from excipients Tables 6-10.

Table 6: Optical Characteristic.

\begin{tabular}{|c|c|c|}
\hline 1 & Detection Wavelength $(\mathrm{nm})$ & 561 \\
\hline 2 & Beer's law limits & 20-Oct \\
\hline 3 & Regression equation $\left(\mathrm{y}^{*}\right)$ & $\mathrm{y}=0.038 \times 0.001$ \\
\hline 4 & Slope $(\mathrm{b})$ & 0.038 \\
\hline 5 & Interept $(\mathrm{a})$ & 0.001 \\
\hline 6 & Correlation coefficient $\left(\mathrm{R}_{2}\right)$ & 0.999 \\
\hline 7 & Limit of Detection $(\mu \mathrm{g} / \mathrm{ml})$ & 0.078 \\
\hline 8 & Limit of quantification & 0.236 \\
\hline
\end{tabular}

Table 7: Determination of Accuracy results for Efavirenz .

\begin{tabular}{|c|c|c|c|}
\hline $\begin{array}{c}\text { Amount of } \\
\text { Sample }(\boldsymbol{\mu g} / \\
\mathbf{m l})\end{array}$ & $\begin{array}{c}\text { Amount of } \\
\mathbf{d r u g} \text { added } \\
(\boldsymbol{\mu g} / \mathbf{m l})\end{array}$ & $\begin{array}{c}\text { Amount Re- } \\
\text { covered }(\boldsymbol{\mu g} / \\
\mathbf{m l})\end{array}$ & \% Recovery \\
\hline 16 & 12 & 11.98 & $99.78 \pm 0$ \\
\hline 16 & 16 & 15.89 & $99.08 \pm 0$ \\
\hline 16 & 20 & 19.99 & $99 . .97 \pm 0$ \\
\hline
\end{tabular}

Table 8: Determination of precision results for Efavirenz.

\begin{tabular}{|c|c|c|c|c|}
\hline $\begin{array}{c}\text { Concen- } \\
\text { tration }\end{array}$ & $\begin{array}{c}\text { Intra-day } \\
\text { Absorbance } \\
\text { Mean } \pm \text { SD }\end{array}$ & \%RSD & $\begin{array}{c}\text { Intra-day } \\
\text { Absorbance } \\
\text { Mean } \pm \text { SD }\end{array}$ & \% Recovery \\
\hline 12 & $0.227 \pm 0.008$ & 0.394 & $0.227 \pm 0.0010$ & 0.461 \\
\hline 16 & $0.458 \pm 0.0008$ & 0.178 & $0.459 \pm 0.0008$ & 0.194 \\
\hline 20 & $\begin{array}{c}0.697 \\
\pm 0.0037\end{array}$ & 0.541 & $0.698 \pm 0.0012$ & 0.173 \\
\hline
\end{tabular}

Table 9: Results of recovery studies for Efavirenz.

\begin{tabular}{|c|c|c|c|}
\hline $\begin{array}{c}\text { Amount of } \\
\text { Sample }(\mu \mathrm{g} / \\
\mathbf{m l})\end{array}$ & $\begin{array}{c}\text { Amount of drug } \\
\text { added }(\mu \mathrm{g} / \mathrm{ml})\end{array}$ & \% recovery \pm RSD & \%RSD \\
\hline 16 & 8 & $99.10 \pm 0.41$ & 0.41 \\
\hline 16 & 10 & $99.58 \pm 0.60$ & 0.64 \\
\hline 16 & 12 & $98.80 \pm 0.88$ & 0.89 \\
\hline
\end{tabular}

Table 10: Results of recovery studies for Sustiva.

\begin{tabular}{|c|c|c|c|}
\hline $\begin{array}{c}\text { Amount of } \\
\text { Sample }(\boldsymbol{\mu g} / \\
\mathbf{m l})\end{array}$ & $\begin{array}{c}\text { Amount of drug } \\
\text { added ( } \mu \mathrm{g} / \mathrm{ml})\end{array}$ & \% recovery \pm RSD & \%RSD \\
\hline 16 & 8 & $98.88 \pm 0.70$ & 0.74 \\
\hline 16 & 10 & $99.75 \pm 0.74$ & 0.78 \\
\hline 16 & 12 & $98.80 \pm 0.51$ & 0.56 \\
\hline
\end{tabular}

\section{References}

1. Ribeiro JA, De Campos LMM, Alves RJ, Lages GP, Pianetti GA (2007) Efavirenz related compounds preparation by hydrolysis procedure: Setting reference standards for chromatographic purity analysis. J Pharm Biomed Anal 43(1): 298-303.

2. Montgomery ER, Edmanson AL, Cook SC, Hovsepian PK (2001) Development and validation of a reverse-phase HPLC method for analysis of efavirenz and its related substances in the drug substance and in a capsule formulation. J. Pharm. Biomed. Anal 25(2): 267-284

3. Weissburg RP, Montgomery ER, Junnier LA, Segretario J, Cook S, et al. (2002) Investigation of critical factors for the resolution of SR695, a key impurity, from efavirenz in the reversed-phase assay of efavirenz dosage forms J Pharm. Biomed Anal 28(1): 45-56.

4. Maurin MB, Rowe SM, Blom K, Pierce ME (2002) Kinetics and mechanism of hydrolysis of efavirenz. Pharm. Res 19(4): 517-521.

5. Gadkari T, Chandrachood P, Shahajietele A, Deshpande N, Salvekar J, et al. (2010) Validated stability indicating LC-PDAMS method to investigate $\mathrm{pH}$ rate profile and degradation kinetics of efavirenz and identification of hydrolysis products by LC-MS. Int. J. Pharm. Sci 2: 169176.

6. Efavirenz monograph (2015) United States Pharmacopeia, USP38, NF33, United States Pharmacopoeial Convention Inc Rockville, CA, USA: 3656 .

7. Efavirenz tablets monograph (2015) United States Pharmacopeia, USP38, NF33; United States Pharmacopoeial Convention Inc, Rockville, CA, USA: 3661.

8. Efavirenz capsules monograph (2015) United States Pharmacopeia, USP38, NF33, United States Pharmacopoeial Convention Inc. Rockville, CA, USA: 3659.

9. Raman NVVSS, Prasad AVSS, Reddy, KR (2011) Strategies for the identification, control and determination of genotoxic impurities in drug substances: A pharmaceutical industry perspective. J Pharm Biomed Anal 55(4): 662-667.

10. Dow LK, Hansen MM, Pack BW, Page TJ, Baertschi SW (2013) The assessment of impurities for genotoxic potential and subsequent control in drug substance and drug product. J Pharm Sci 102(5): 14041418.

11. Robinson DI (2010) Control of Genotoxic Impurities in Active Pharmaceutical Ingredients: A Review and Perspective. Org Proc Res Dev 14(4): 946-959.

12. Elder DP, Lipczynski AM, Teasdale A (2008) Control and analysis of alkyl and benzyl halides and other related reactive organohalides as potential genotoxic impurities in active pharmaceutical ingredients (APIs). J Pharm Biomed. Anal 48(3): 497-507.

13. Bolta HM, Fothb H, Hengstlerc JG, Degena GH (2004) Carcinogenicity categorization of chemicals-New aspects to be considered in a European perspective. Toxicol. Lett 151(1): 29-41.

14. Boyle GA, Edlin CD, Li YF, Dennis CL, Garreth LM et al. (2012) Enantioselective synthesis of the carbocyclic nucleoside abacavir [J]. Org Biomol Chem 10(9): 1870-1876.

15. Shibata T, Morioka H, Hayase T, Kaori Choji, Kenso Soai (1996) Highly enantioselective catalytic asymmetric automultiplication of chiral pyrimidyl alcohol [J]. J Am Chem Soc 118(2): 471-472.

16. Tan L, Chen CY, Tillyer RD, Grabowski EJJ1, Reider PJ (1999) A novel, highly enantioselective ketone alkynylation reaction mediated by chiral zinc aminoalkoxides [J]. Angew Chem Int Ed 38(5): 711-713.

17. Pierce ME, Parsons Jr RL, Radesca LA, Young S. Lo, Stuart Silverman, et al. 1998) Practical asymmetric synthesis of efavirenz (DMP 266), an HIV-1 reverse transcriptase inhibitor [J]. J Org Chem 63(23): 85368543. 

(C) Commons Attribution 4.0 License

DOI: 10.19080/OMCIJ.2019.08.555739
Your next submission with Juniper Publishers will reach you the below assets

- Quality Editorial service

- Swift Peer Review

- Reprints availability

- E-prints Service

- Manuscript Podcast for convenient understanding

- Global attainment for your research

- Manuscript accessibility in different formats

( Pdf, E-pub, Full Text, Audio)

- Unceasing customer service

Track the below URL for one-step submission https://juniperpublishers.com/online-submission.php 